\title{
The effect of specimen processing on radiolabeled monoclonal antibody biodistribution
}

\author{
Richard L. Wahl, Philip Sherman, and Susan Fisher \\ Department of Internal Medicine, Division of Nuclear Medicine, University of Michigan Medical Center, \\ Ann Arbor, MI 48109, USA
}

\begin{abstract}
Monoclonal antibodies are assuming increasing importance in experimental and clinical medicine. Generally, tissue biodistribution studies in animals precede human studies. To investigate a concern of ours that varying methods of sample handling in these studies could result in apparent alterations in tissue-binding levels, we compared two methods of tissue processing after the administration of labeled antibodies: one including only blotting away of blood, the other involving several washing steps. The unwashed, blotted specimens were found to have significantly more radioactivity per gram of tissue than the washed, ranging from $22 \%$ more in the spleen to $52 \%$ more in the lungs and left ventricle. Since in vivo imaging is dependent on the total mount of radioactivity in an organ, we believe the most meaningful determination of tissue radioactivity should be based on unwashed samples. Awareness of this problem is suggested to allow meaningful extrapolations from measured tisue localization data to imaging and therapy.
\end{abstract}

Radiolabeled monoclonal antibodies hold great promise as specific imaging agents in nuclear medicine and as carriers of therapeutic radionuclides to tumors. Many laboratory studies are ongoing in animal model systems, evaluating the degree of labeled antibody localization. In many of these studies, relatively high levels of blood pool activity are present, especially at early time points after administration of the intact labeled antibody (Ballou et al. 1979; Wahl et al. 1983). Although the use of $F\left(a b^{\prime}\right)_{2}$ fragments has decreased this problem somewhat, moderate blood levels are still being seen (Wahl et al. 1983b). This problem has been approached in clinical imaging by background subtraction methods (Goldenberg et al. 1978; Mach et al. 1981). In laboratory animals, however, this problem of high blood-background levels seemed a potential source of confusion in interpreting laboratory data.

Since labeled antibodies, at relatively early time points after injection are both in the blood-stream and in the target tissues, it seemed that the apparent radioactivity in the tissue would be dependent on how much blood pool activity was removed in sample processing. A variety of approaches

This work was supported in part by D.O.E. Contract no. DEAC02-76EV02021

Offprint requests to: Richard L. Wahl, M.D. to sample processing have been described in the literature including: exhaustively perfusing the experimental animals with saline to remove all blood (Koji et al. 1980); mincing and homogenizing the tissue and washing repeatedly, blending and weighing the wet specimen (Bernhard et al. 1983), washing tissues several times in phosphate-buffered saline "to get rid of as much blood as possible" (Ghose et al. 1975); lightly blotting surface blood from the target tissues, weighing and counting them with contained blood present (Wahl and Parker 1983c); carefully removing the tissue, weighing and counting (Hoffer et al. 1973); and not clearly specified which we assume to mean simple excision and counting (Primus et al. 1973).

The lack of uniformity in the literature in sample processing is not surprising; however, we were concerned that these different methods might give different results for the same radiopharmaceutical. To evaluate the importance of this potential problem on localization studies, we elected to investigate the behavior of a radiolabeled non-specific monoclonal antibody using two different modes of sample processing, one preserving blood content, the other depleting to some extent blood content, through repeated washings.

\section{Methods}

UPC-10 mouse myeloma protein (IgG-2a kappa) of no known tissue specificity was purchased from Litton bionetics as a purified product. This was radiolabeled with ${ }^{125} \mathrm{I}$ using a modification of the method of Hunter and Grenwood (Greenwood et al. 1963); $100 \mu \mathrm{g}$ was labeled to an activity of $70 \mathrm{Ci}$. This was passed over a biorad P-60 gel exclusion-column to separate free from bound ${ }^{125} \mathrm{I}$. Antibody purity was confirmed on SDS polyacrylamide gel electrophoresis using a $7.7 \%$ gel. Five normal female Sprague Dawley rats (Harlan-Sprague Dawley, Indianapolis, IN) were injected with $15 \mathrm{Ci}$ of ${ }^{125} \mathrm{I}$ UPC-10 (approximately $20 \mu \mathrm{g}$ ) via a femoral vein cut-down. Animals were killed $24 \mathrm{~h}$ after injection, immediately after blood samples were obtained.

Four similar-sized aliquots from the liver, kidney, lung, spleen, and left ventricle were removed. Tissues obtained from each animal were immediately blotted to remove excessive blood, then either weighed or washed in phosphatebuffered saline solution. The tissue aliquots for washing were washed in serial petri dishes with saline, incised in several locations, washed two more times, blotted, and 
Table 1. Percentage of injected dose per kilogram per gram of tissue with and without washing

\begin{tabular}{llll}
\hline & Washed & Unwashed & $\%$ Difference \\
\hline Liver & $0.0523 \pm 0.003$ & $0.0689 \pm 0.002$ & $32 \% *$ \\
Kidney & $0.0589 \pm 0.006$ & $0.083 \pm 0.005$ & $40 \% *$ \\
Spleen & $0.0638 \pm 0.005$ & $0.078 \pm 0.004$ & $22 \% *$ \\
Left ventricle & $0.0633 \pm 0.005$ & $0.097 \pm 0.003$ & $52 \% *$ \\
Lung & $0.133 \pm 0.022$ & $0.202 \pm 0.011$ & $52 \% *$ \\
Blood & & $0.403 \pm 0.018$ & $0 \%$ \\
\hline
\end{tabular}

Mean of 10 specimens \pm SEM.

$* P=<0.0001$

Table 2. Rank order of tissue radioactivity per gram before and after washing

Unwashed:

Blood $>$ lung $>$ left ventricle $>$ kidney $>$ spleen $>$ liver

Washed:

Blood $>$ lung $>$ spleen $>$ left ventricle $>$ kidney $>$ liver

weighed. Tissues processed by blotting once or by three washings were counted at the ${ }^{125} \mathrm{I}$ channel in a gamma counter. After correction for physical decay, the percentage of the injected dose per gram of tissue was calculated (with normalization to a $1000-\mathrm{g}$ animal), i.e., $\% \mathrm{~kg}$ dose/g. Thus each animal and tissue served as its own control for the two different sample processing methods. Differences between means were calculated using the paired two-column $t$-test.

\section{Results}

As illustrated in Table 1, there are significant differences between the blotted only and the blotted and washed tissues radioactivity $(p<0.0001)$. These differences are least striking for the spleen with a $22 \%$ change and most striking for the left ventricle and the lungs (with the blotted only specimens having $52 \%$ more activity than the washed specimens). The unwashed tissue from the vascular spleen, liver, and kidneys are $22 \%, 32 \%$ and $40 \%$ greater in activity per gram than the comparable washed tissues. Blood pool activity is relatively high at twice lung activity at this early time point. In addition, the relative amount of radioactivity among the tissues studied varied with and without washing (Table 2).

\section{Discussion}

These data show that marked differences can occur in the apparent tissue distribution of labeled antibodies simply due to minor alterations in sample processing after sacrifice. Although this phenomenon has been shown with radiolabeled serum albumin and exhaustive perfusion of animals with saline (Bauer et al. 1955), we were surprised at the magnitude of the changes we saw. While initially expecting only the relative amounts of radioactivity in the tissues which were washed to drop, it was noted that the drops were variable and, as is shown in Table 2 , the relative amounts of radioactivity per gram of tissue varied, so that spleen is higher relative to other washed tissues after wash- ing than it was prior to washing. As would be expected, the left ventricle drops in activity both absolutely and relatively compared to the other tissues with washing, presumably largely due to washing away of blood pool activity.

These changes after washing would likely be much smaller if less of the radioactivity was initially present in the blood pool, as is the case with many other radiopharmaceuticals and with antibodies that localize very well. These changes in absolute and relative tissue radioactivity content, with simple modifications in processing, are also surprisingly large, particularly because we did not attempt exhaustively to remove all contained blood.

Although no tissue to which the antibody was specifically directed was studied, it is probable that such a tissue would retain radioactivity better than one in which much of the radiolabeled antibody was loosely bound. If this were the case, then tumor to background ratios could be artifactually inflated (though not tumor/blood ratios). Further work on this question is necessary.

Although it is intellectually appealing to know how much radioactivity is in the liver without the surrounding blood's contribution, it seems to us that what is important in nuclear imaging, and possibly therapy, is the total radioactivity in the organ (including that due to the blood pool activity) relative to background, rather than that radioactivity which is not easily washed away from the organ. When nuclear images are obtained using radiolabeled antibodies, the organs are not washed free of blood, and background subtraction of this blood activity has been necessary in many studies (Mach et al. 1981). For these reasons, we feel it may be more meaningful in attempts to extrapolate animal tissue distribution work with labeled antibodies to human imaging studies, to report tissue radioactivity accumulation data with a specimen processing method including blotting only for excess surface blood. Care should be taken not to include extensive washings which, as demonstrated here, remove much radioactivity, probably largely situated in the washed organ's blood pool.

\section{References}

Ballou B, Levine G, Hakala TR, Solter D (1979) Tumor location with radioactively labeled monoclonal antibody and external scintigraphy. Science 206:844 846

Bauer FK, Tubis M, Thomas HB (1955) Accumulation of homologous radioiodinated albumin in experimental tumors. Proc Soc Exp Biol Med 90:140-142

Bernhard MI, Hwang KM, Foon KA, Keenan AM, Kessler RM, Frincke JM, Tallam DJ, Hanna MG, Peters L, Oldham RK (1983) Localization of ${ }^{11} \mathrm{In}$ - and ${ }^{125} \mathrm{I}$-labeled monoclonal antibody in guinea pigs bearing line 10 hepatocarcinoma tumors. Cancer Res 43:4429-4433

Ghose T, Guclu A, Tai J, MacDonald AS, Norvell ST, Aquino $J$ (1975) Antibody as carrier of ${ }^{131} I$ in cancer diagnosis and treatment. Cancer 36:1646-1657

Goldenberg DM, De Land FH, Kim EE, Bennett S, Primus FJ, van Nagell JR, Estes N, De Simone P, Rayburn P (1978) Use of radiolabelled antibodies to carcinoembryonic antigen for the detection and localization of diverse cancers by external photoscanning. New Engl J Med 298:1384-1388

Greenwood F, Hunter W, Glover J (1963) The preparation of ${ }^{131}$ I-labelled human growth hormone of high specific radioactivity. Biochem J 89:114-118

Hoffer PB, Lathrop K, Bekerman C, Franz V, Refetoff S (1973) Use of ${ }^{131}$ I-CEA antibody as a tumor scanning agent. J Nucl Med 15:323-327 
Koji T, Ishii N, Munehisa T, Kusumoto Y, Nakamura S, Tamenishi A, Kobayashi K, Hara A, Tsukada Y, Nishi S (1980) Localization of radioiodinated antibody to alpha-fetoprotein in rats with transplanted hepatocellular carcinoma. Oncodev Biol Med $1: 359-368$

Mach J-P, Buchegger F, Forni M, Ritschard J, Berche C, Lumbroso J-D, Schreyer M, Girardet C, Accola R, Carrel S (1981) Use of radiolabelled monoclonal anti-CEA antibodies for the detection of human carcinomas by external photoscanning and tomoscintigraphy. Immunol Today 2:239-249

Primus FJ, Wang RH, Goldenberg DM, Hansen HJ (1973) Localization of human GW-39 tumors in hamsters by radiolabeled heterospecific antibody to carcinoembroyonic antigen. Cancer Res 33:2977-2982

Wahl RL, Philpott GW, Parker CW (1983a) Monoclonal antibody radioimmunodetection of human-derived colon cancer. Invest Radiol 18:58-62

Wahl RL, Philpott GW, Parker CW (1983b) Improved radioimaging and tumor localization with monoclonal $\mathrm{F}\left(\mathrm{ab}^{\prime}\right)_{2} \mathrm{~J}$ Nucl Med 24:316-325

Wahl RL, Parker CW (1983c) Monoclonal antibody radioimmunodetection of transplant rejection. J Nucl Med 24:81

Received February 18, 1984 